\title{
ИМАГОЛОГИЯ
}

УДК $82.091+821.161 .1$

DOI: $10.17223 / 24099554 / 10 / 5$

\section{В.С. Киселёв}

\section{ИТАЛИЯ В ИСТОРИОСОФСКИХ ПРЕДСТАВЛЕНИЯХ И ТВОРЧЕСТВЕ М.Н. МУРАВЬЕВА}

Выявляются основные мотивы, характерные для рецепции итальянской культуры в историко-философских и художественных произведениях М.Н. Муравьева. Показывается ключевая роль итальянского Возрождения, которое становится для писателя историческим образцом в осмыслении будущего русской культуры. Выделены доминанты в восприятии М.Н. Муравьевым итальянской музыки, живописи и литературы.

Ключевые слова: русско-итальянские литературнье связи, ХVIII век, Н.А. Львов, М.Н. Муравьев, Италия, итальянское Возрождение, итальянская опера, итальянская живопись, итальянская литеpamypa.

В русском культурном сознании Италия занимает особое место, определяемое ощущением глубинного родства. Вряд ли можно найти более точные слова для его выражения, чем это сделал в начале XX в. Н.А. Бердяев: «Русская тоска по Италии - творческая тоска, тоска по вольной избыточности сил, по солнечной радостности, по самоценной красоте. $<\ldots>$ Италия обладает таинственной и магической силой возрождать душу, снимать тяжесть с безрадостной жизни. Такова вечная, неумирающая, неразрушимая Италия» («Чувство Италии», 1915) [1. С. 368-369]. Не одно поколение русских и итальянских ученых посвятило свои усилия изучению исторических форм и, главное, духовной сути этого взаимного тяготения.

В истории русско-итальянских литературных отношений XVIII век занимает особое место - это время взаимного открытия культурных миров, когда познание чужого художественного опыта помогало выявить характерные черты и перспективы развития своего искусства. Как справедливо отметил В.И. Рутенбург, «несмотря на своеобраз- 
ные условия развития России и Италии, их связывали некоторые общие черты или сходные проблемы внутренней политики, экономики, культуры» [2. С. 11] (см. также: [3]). Пожалуй, главной из этих проблем было национальное самоопределение: обе страны осознавали себя как еще не сыгравшие своей - и значительной - роли в жизни Европы. В случае Италии богатейшее культурное наследие, привлекавшее художников, архитекторов, литераторов самых разных стран, разительно контрастировало с политической раздробленностью и экономической слабостью. Это противоречие остро ощущали русские путешественники, как, например, Д.И. Фонвизин: «Рады мы, что Италию увидели; но можно искренно признаться, что если б мы дома могли так ее вообразить, как нашли, то, конечно, бы не поехали. Одни художества стоят внимания, прочее все на Европу не походит» [4. С. 537]. В случае России ситуация мыслилась как прямо противоположная: растущая военно-политическая и экономическая мощь опережала развитие искусств. Особенно остро давала о себе знать слабость отечественной культурной традиции, на которую могло бы опереться европеизированное национальное сознание. Тем самым Россия и Италия выступали как две своеобразные взаимодополнительные сферы, предлагающие актуальные друг для друга модели развития.

Именно эта мысль выступила структурообразующим моментом для рецепции Италии в историософии и творчестве М.Н. Муравьева. Этот итальянский план, заметим, при все усиливающемся интересе к автору «Богине Невы» и «Эмилиевых писем» (см. показательные казанские сборники «Михаил Муравьев и его время» [5]) еще не становился объектом самостоятельного изучения, хотя у Муравьева мы найдем и ряд переводов из итальянской поэзии, и многочисленные высказывания об итальянских поэтах, музыкантах, живописцах, и даже опыты синтетического осмысления итальянского искусства и истории. В совокупности они составляют важный пласт творческого наследия писателя, ценный и сам по себе, и в свете более масштабных и глубоких итальянских увлечений ученика и воспитанника Муравьева К.Н. Батюшкова [6], генезис которых позволяют объяснить.

Инициатором интереса к Италии и источником важнейших суждений об итальянской культуре был для Муравьева Н.А. Львов. С ним молодой поэт познакомился в 1773 г., когда поступил на службу в лейб-гвардии Измайловский полк (Львов тогда служил в Преобра- 
женском), и отношения быстро переросли в крепкую, интеллектуально насыщенную дружбу. Львов, человек энциклопедических интересов, поэт, художник, архитектор, был тесно связан с художественными сферами, где влияние итальянского искусства и интерес к Италии ощущались сильнее всего. Одну из них представляла опера, с которой русская публика была хорошо знакома уже со времен Анны Иоанновны [7. С. 398 и далее]. Львов, впоследствии сам автор нескольких комических опер («Сильф», «Ямщики на подставе», «Милет и Милета», «Парисов суд»), итальянскую оперу очень ценил и мог гордиться своим знакомством с П.А.Д. Метастазио, «первым нашего века драматическим стихотворцем» [8. 270], с которым встретился в Вене в 1781 г. на обратном пути из Италии.

Эту музыкально-драматическую любовь вполне разделял и Муравьев. В его письмах и сочинениях регулярно упоминаются итальянские певцы и авторы опер, которых он мог слышать в столицах. Так, 4 декабря 1777 г. он писал сестре: «Я, сударыня, был в маскераде и застал несколько оперы: играли “Лучинду”, последнюю пьесу нашего Колтелини» [9. С. 323] ${ }^{1} .29$ января 1778 г. Муравьев сообщал отцу, что «третьего дня была итальянская опера “Ахиллес"» [Там же. C. 343$]^{2} .25$ февраля того же года он «слушал целую мессу в католицкой церкви, и Порри пел» (письмо от 26 февраля) [Там же. С. 352] ${ }^{3}$. Увлечение итальянской оперой сохранилось у писателя на всю жизнь и отразилось в том числе и в стихах:
Вливались по чреде во чувства обольще́нны
То Метастазьевы творения священны,
Точащи сладостна витийствия соты,
В которых таяла, о Бонафини, ты!
То Колтельиньевы разительны черты,
Восторга полными согласьями одеты,
Заченьшемись в душе примрачного Траеты... [10. С. 205].

Это перечисление музыкальных впечатлений юности - Метастазио, итальянская певица Бонафини, гастролировавшая в России, и

\footnotetext{
${ }^{1}$ Речь идет о «Люцинде и Армидоре», музыкальной драме итальянского драматурга Марко Колтеллини, жившего в конце 1760-1770-х гг. в Петербурге (музыка Джованни Паизиелло, с 1776 по 1783 г. придворного капельмейстера и директора итальянской оперы в Петербурге).

${ }^{2}$ Имеется в виду «Ахилл во Сциросе» Метастазио (музыка Паизиелло).

${ }^{3}$ Порри - известный итальянский оперный певец.
} 
композитор Томмазо Траетта, здесь работавший, уже упоминавшийся Колтеллини - завершается, однако, в «Сожалении младости» знаменательным переходом к патриотической теме с упоминанием И.И. Шувалова, известного итальянскими симпатиями, и его «любимца»- М.В. Ломоносова:

Наставлен чтением, иль лучше - обольщен, При слове «отчество» я зрелся восхищен И образ оного мечтательный составил Из черт, которые в душе моей оставил Певец величия, героев и заслуг Что был Шувалова любимец или друг [10. С. 206].

Тема «отечества» применительно к музыкальному итальянскому контексту являлась устойчивой для Муравьева. В частности, она возникла в так называемом «феонином цикле» во фрагменте «Алетов», где главным героем становился молодой человек, недавно возвратившийся из заграничного путешествия:

Алетов $<\ldots>$ тотчас сел за клавесины и зачал играть и петь итальянскую арию.

Г. То́полов. Ария очень хороша. Позвольте спросить мне, чья она, кто сочинитель?

Г. Алетов. Паизиелло. Это из последней его оперы.

Г-жа Осанова. Паизиелло! Мой учитель. Он бывал у нас каждый день в Петербурге. Я не могу вспомнить его уроков без особливого удовольствия. Какой любезный человек кроме дарования его! Какой веселый! Как жаль, что он не остался в России!

Г. Алетов. Ему теперь очень хорошо в Неаполе. Король его жалует, все его любят. Сочинения его нравятся обществу. Чего ж ему желать более, когда он все это находит в своем отечестве? В прекрасном климате, и в таком большом городе, как Неаполь.

Феона. Особливо в отечестве. Я с вами совершенно согласна. Не помните эти прекрасные стихи Бернисовы: нигде солнце не сияет так ясно, нигде нет такого чистого воздуха, такой прозрачной воды, как в том месте, где мы увидели свет (цит. по: [11. С. 144-145]).

Вторая сфера, к которой Львов приобщил молодого писателя, была художническая. Львов дружил с Д.Г. Левицким и В.Л. Боровиковским, позднее поддерживал А.Е. Егорова и И.А. Иванова, сохранял тесные связи с Академией художеств, почетным членом которой был избран в 1787 г. Академия художеств, заметим, во второй половине XVIII в. являлась одним из важнейших институтов, поддержи- 
вавших связи с Италией. На ее попечении в Риме находилась небольшая колония русских пенсионеров, художников, скульпторов, архитекторов, знакомящихся с искусством древности и современности $[12,13]$, а усилиями меценатов (И.И. Шувалов, М.И. Воронцов, Д.А. Голицин и др.) постоянно пополнялась коллекция оригиналов и копий итальянской классики. За трудами Академии Муравьев, как и его друг Львов, пристально следил, видя в них очевидный залог совершенствования отечественного искусства. Так, он с восторгом сообщал отцу 3 июля 1778 г.: «Нынешнюю неделю отворена Академия художеств. Не было дня <..>, в который бы ни пробыл я там по крайней мере двух часов. Я не могу удержаться от радости, что сей вкус мною владычествует» (цит. по: [10. С. 340]).

Своеобразным камертоном «сего вкуса» выступало искусство итальянского Возрождения, о котором Муравьев мог получать сведения из первых рук: за свое короткое путешествие по Италии Львов смог познакомиться с лучшими собраниями картин Неаполя, Рима, Ливорно, Пизы, Флоренции, Болоньи и Венеции. Более того, в их оценке Львов выступал проводником новых плодотворных идей, опирающихся на труды И.-И. Винкельмана [14. С. 33-40]. Отзвуки этого путешествия неоднократно встречаются и в творчестве Муравьева. В «Берновских письмах» автобиографический повествователь обращается к своему товарищу:

Завидую тебе, любезный друг мой. <...> Ты наслаждался сим чистым небом Неаполя, сими зрелищами природы, роскошной и ужасной, прелестной в самих ужасах. Ты посещал сии мирные долины, внушающие приятную задумчивость, которые служили образцом Елисейских полей, и ты видел курящиеся острова сии, где было некогда шумное царство Эола [15. С. 163].

Эти мечты о природе Италии соседствуют здесь же с замечаниями сугубо художественными, навеянными путешествиями русских пенсионеров:

У нас гостит молодой человек, питомец Академии художеств, возвращающийся из путешествия своего в Италию. Исполненный ревности к своему искусству и пораженный еще свежим воспоминанием бессмертных картин Рафаела, Корреджия, Тициана, исчисляет он с жаром красоты их, и мы разделяем восторг его [Там же. С. 151].

По мнению Муравьева, одно только равнение на высшие образцы способно служить возвышению русского искусства, поэтому у луч- 
ших отечественных художников он подчеркивает те особенности, которые приближаются к идеалу итальянской живописи. Причем в этом Муравьев стремится к дифференцированности суждения, обращая внимание на гармоничную четкость рисунка Рафаэля, специфическую светотень Тициана, колорит Корреджо:

Природу видел я под кистию Лосенка,

Жива Левицкого малейшая оттенка,

Российских вижу вкруг художников труды.

Стремитесь, образцов достигните среды

Да будет красоты идея вами зрима.

Явите чудеса Венеции и Рима,

Черты Рафаеля и Тициана тень,

$<\ldots>$

И, граций оживив в изображенье свежем,

Что живописцы вы, почувствуйте с Коррежем [10. С. 173].

Самому Муравьеву, занятому воспитанием великих князей, а затем многочисленными общественными обязанностями, не представилась возможность воочию увидеть произведения мастеров, о которых он писал, но и знакомство опосредованное - через копии и суждения художников-друзей - порождало очень тонкие разборы. В них уже предчувствовались романтические веяния, акцентирующие в картинах итальянского Возрождения субъективное воздействие, «расширение души», используя слова Жуковского, и выход в иной, идеальный план бытия [16]. Образцом здесь могут служить характеристики Рафаэля из статьи «Искусства в Италии»:

Тогда были прекрасные дни новой Италии, когда бессмертные художники говорили всеми чувствами воображению $<\ldots>$, когда небесное воображение Рафаэля представило истинное и неприступное сияние Божества в величественной картине Преображения $<\ldots>$ они (картины Тициана) могут соревновать с видимою природою; но Рафаэль дерзал представить кистию своею неосязаемый вид вышних существ и действовать над душою и разумом зрителя [17. С. 175-176].

В неменьшей степени подобное «действие над душой» совершала и поэзия. К итальянской словесности Муравьев начал приобщаться в 1776 г., когда вместе с Львовым принялся за изучение итальянского языка. В «Журнале на 1776 год», своеобразном творческом дневнике, результатом этих усилий явился ряд небольших переводов из Т. Тассо (начало «Освобожденного Иерусалима»), Дж. делла Каза («Сонет к Тициану»), Дж. Триссино (начало поэмы 
«Италия, избавленная от готов») и Метастазио («Сонет», «Милосердие Титово», в 1779 г. - «Смерть Катонова»). Позднее, в 1780-е гг., к ним добавились переводы из Петрарки «Вы, слушающие в разбросанных стихах...», из «Адониса» Дж. Марино, из «Неистового Роланда» Л. Ариосто и вновь из Метастазио («Кантата третья на десять»). Сам Муравьев относился к данным переводам как к учебным, полезным для постижения языка и выработки стиля. Для печати они не предназначались, оставаясь на уровне незавершенных набросков. Единственное, пожалуй, исключение было сделано для перевода из Тассо, несколько строк которого - обращение к Музе - писатель передал повествователю «Берновских писем»:

Ты знаешь: свет таков, в нем боле привлекает

Согласием своим прельщающий Парнас

И в самыя сердца слабейшия вникает

Со сладостью стихов священный правды глас.

Так отроку даем, недугом сокрушенну,

Мы чашу с врачеством, но медом орошенну,

Полынно питие обманут отрок пьет

И возвращая жизнь обманом восстает [15. С. 174].

Этот акцент, очевидно, не случаен. Имя Тассо и рядом с ним Ариосто чаще всего упоминается в произведениях Муравьева. Для русского литературного сознания XVIII в. они олицетворяли в себе итальянскую версию эпопеи, высшего жанра классицистической «табели о рангах». В таком качестве они фигурируют и у Муравьева:

Эпопея есть верх превосходства в поэзии. Все опыты в оной требуют нашего почтения. Творцы Илиады, Энеиды, Фарсалы, Иерусалима, Потерянного рая, Мессиаса, Генриады, Россиады, суть умы другого чина, нежели Марциал, Катулл, Шолье, Проперций и сам Гораций, если бы он не был первый из лириков [17. С. 315].

Дневниковые записи свидетельствуют о том, что «Освобожденный Иерусалим» Муравьев, хотя и с трудом, прибегая к помощи Львова, уже в 1770-е гг. прочел в оригинале и полностью, а потому мог составить адекватное представление о своеобразии поэмы (напомним, что к моменту чтения на русском языке существовал только прозаический перевод М.И. Попова 1772 г. с французского переложения). С «Неистовым Роландом» поэт познакомился позднее и воспринял Ариосто уже в свете традиции Тассо. Муравьева более всего привлекло в ней созвучное его собственному вкусу и интересам его круга, в частности 
M.M. Хераскова, эмоционально-фантастическое начало, свидетельство преромантических устремлений. Оно служило обновлению эпоca, сближению его с формирующейся романической поэтикой. Как справедливо указала Р.М. Горохова, влияние Ариосто и Тассо сильно ощущается в архитектонике, образах и сюжетных линиях херасковской «Россиады» $[18,19]$. Эти моменты глубже всего запали и в память Муравьева, который высоко ценил создание своего старшего друга и наставника, видя в нем свидетельство выхода отечественной литературы на европейский уровень:

Трубою мог звучать великий Ломоносов

И тот, что проводил в Чесмесски волны россов.

Не празден дух его, и со Вергильем Тасс

Увидят своего соперника у нас.

(«Опыт о стихотворстве») [10. С. 135].

Ты вырываешь кисть из рук у Ариоста, Животворящу кисть, которыя черты

И в своенравии не тратят красоты.

(«Сожаление младости») [Там же. С. 204].

Героические и в то же время фантастические образы Ариосто и Тассо, в особенности навеянные эпизодом с очарованным заключением Ринальда на острове Армиды, неоднократно появятся у Муравьева в «Послании о легком стихотворении», «Опыте о стихотворстве», в «Обаянии любви» и «К И.Ф. Богдановичу» и др. ${ }^{4}$ В оценке Тассо, данной в «Берновских письмах», яснее всего высказалось это тяготенье Муравьева к эмоциональности, яркой характералогии и занимательности:

Он перенял у Гомера искусство ознаменовать отличными чертами толпу героев и нести к одному концу множество привлекательных приключений. Твердое благоразумие Годофреда, вождя христианского воинства, противоположно коварности Аладина, султана Иерусалимского. В Ринальде соединены все прелести юности и все восторги запальчивой храбрости. Тасс воспользовался сиянием, которое предлагали ему рыцарские нравы и древние предания, и вместо гомерова баснословия упо-

${ }^{4}$ См., напр.: Армидин остров что, когда не ощущенье, Не повесть зиждимых любовию чудес, Котору Тасс нашед, нам в басню перенес? Чье твердо сердце, зря Ринальда в заблужденье, Стоически ему предпишет осужденье? [Там же. С. 230]. 
требил верование того времени в волшебство. Может быть, излишними чудесами наполнил поэму свою [15. С. 173].

Последняя претензия в еще большей степени относилась к Ариосто, поэму которого Муравьев называл «игривыми вымыслами» и предостерегал ее неосторожных подражателей: «Сколько сказок обезобразили ложную или истинную историю Роландов и Ринальдов <...>. Однако сии сказки продолжают еще нравиться» [20. Л. 75]. Причиной тому в случае Ариосто являлась яркая живописность и музыкальность - черта, неизменно акцентируемая Муравьевым и входящая в его идеал взаимодополнительности живописи, поэзии и музыки:

Чтобы возвыситься, поэзия должна
Из живописи быть с музыкой сложена.
Достоин Ариост идти с Паизиелом.
(«Послание о легком стихотворении») [10. С. 222].

Стоит заметить, однако, что и противоположность «Неистового Роланда» - строгая героическая поэма - тоже не вызывала сочувствия Муравьева. В частности, «Италия, избавленная от готов» Дж. Триссино, провозвестница классицистического эпоса, удостоилась лишь самого поверхностного знакомства и перевода нескольких начальных стихов. Гораздо плодотворнее оказался опыт «легкой поэзии», элементами которой были насыщены поэмы Ариосто и Тассо. В этом смысле их имена вполне закономерно появились в процитированном выше «Послании о легком стихотворении».

В 1780-1790-е гг., когда Муравьев отошел от больших классицистических форм и все более вносил в свою поэзию психологизм, рефлексию, музыкальность, больший интерес у него начали вызывать итальянские лирики. Это чувствовалось уже по направленности переводов. Если в 1770-е гг. он, например, из большого корпуса произведений Метастазио выбирал тексты с эпико-драматическим потенциалом - «Милосердие Титово», «Смерть Катонова» (монологи из оперных либретто), то в 1780-е гг. Муравьев у того же Метастазио переводит лирические фрагменты («Кантата третья на десять»). В круг увлечений поэта включались и образцы любовной лирики Ф. Петрарки, и галантные стихи Дж. Марино, и пасторальная поэзия, которые он более всего ценил за обработанность языка и стиля, за способность передавать тончайшие нюансы мысли и чувства. 
«Щастливый разум Петрарка, - читаем мы, в частности, в “Берновских письмах", - воскресив дух древних письмен даровал стихотворство Италии, в которой из остатков Латинского языка составлялся новый, полный гибкости и гармонии» [15. С. 172-173].

Схожую задачу, по мнению Муравьева, могла выполнить в России легкая поэзия - и сравнения с Петраркой, Марино, Метастазио пронизывают послания к лучшим отечественным стихотворцам И.Ф. Богдановичу, Н.А. Львову, Я.Б. Княжнину. Собственная практика Муравьева тоже внесла существенный вклад в подобную обработку. Как показали исследования С. Гардзонио и В.Н. Топорова, при весьма малом количестве собственно переводов Муравьев стремился к стиховой адаптации целостных словарно-образных и строфико-метрических моделей, предлагаемых полюбившимся оригиналом [21; 22. С. 764-800]. Так, единичные переводы из того же Метастазио дополнялись оригинальными вариациями по модели его кантат «Отъезд», «Свобода», «Скромная любовь». В результате же освоению подвергался не только конкретный текст, но и определенный стиль, форма поэзии, вид искусства.

Этот метод идеально соответствовал культурно-эстетической концепции Муравьева, в рамках которой искусство итальянского Возрождения, главный предмет его интереса, служило непосредственным образцом для искусства отечественного, входящего в период собственного Ренессанса. О причинах, условиях и ходе итальянского Возрождения писатель задумывался неоднократно, видя в нем очевидную модель для России. Отправной точкой его размышлений выступало сближение древней допетровской Руси и европейского Средневековья. В «Берновских письмах», в статьях «Успехи человеческого разума», «Искусства в Италии» и ряде других Муравьев, следуя мысли Просвещения, оценивал его как эпоху тьмы и невежества. «Разлитие северных народов опровергло сие величественное здание Римской империи и исторгло семена вкуса и письмен, - писал он о Европе. - Целые столетия разорительное варварство ожесточало человеческий род» [15. С. 172]. Схожую характеристику получила и древнерусская культура, которой Муравьев отказывал в познавательной ценности и художественном достоинстве, констатируя, например, в статье «Художества Российские»: «Довольствуясь возбуждать набожество молящихся, живописцы наши не ревновали последовать природе и не искали прекрасного в укра- 
шении храмов» [23. С. 185]. Только стечение многих благоприятных исторических обстоятельств, среди которых Муравьев называет и преодоление феодальной раздробленности («удельного правления»), и объединяющую роль церкви, и крестовые походы, позволившие вновь узнать греческое искусство, и экономическое развитие с его проснувшимся вкусом к роскоши - все это помогло Европе преодолеть варварство и обратиться к античным первоистокам, возрождая науки и искусства:

В сем спокойствии $<\ldots>$ нравы приобрели некоторую степень возвышения, и усыпленный разум человеческого рода стал чувствительно пробуждаться. Писания великих творцов Августова века были извлечены из праха $<\ldots>$ и Петрарк с благоговением читал Вергилия. Ученые греки, ушедшие в Италию по взятии Константинополя, принесли с собой вкус греческих письмен, принятых с восторгом очарования [17. С. 183-184].

Намеки на подобный процесс Муравьев видел и в России, где они, однако, оказались прерванными в связи с затянувшейся централизацией и трудностью межкультурного общения в эпоху татарского ига: «Связи России с упадающею Грециею долженствовали бы переселить ранее в отечество наше просвещение и вкус художеств, если бы несчастное нападение татарское не отвлекло внимания предков наших на единственную цель защищения» (цит. по: [24. С. 356]). Однако Муравьев с особенным удовлетворением отмечал, что как только иго было свержено и «уделы соединились в единое политическое тело, так скоро первые взоры государя обратились к искусствам Запада» [Там же. С. 356]. В заметке «Аристотель Болонский» писатель чрезвычайно высоко оценивал роль этого знакомства, начавшего совершаться уже в XV в. Привнесенный итальянским архитектором Аристотелем Фьорованти готический элемент послужил предвестием истинного искусства Возрождения, наложив свой отпечаток на облик Москвы, в которой «путешественники узнают некоторые черты сходства с Венециею» [Там же. С. 356].

Тем не менее истинное Возрождение наступило в России, по мнению Муравьева, только в правление Петра: «Знаменитая эпоха преобразования России Петром I стала эпохою и искусств Российских» [23. С. 186]. Покровительство монарха и его вельмож позволило русским художникам и поэтам приобщиться в XVIII в. уже не к готике, а к подлинному античному искусству, в чем посредником выступало искусство Италии. Заметим, что в характеристике 
итальянского Возрождения Муравьев подчеркивал влияние сиятельных меценатов:

Папы, основав свое могущество на силе мнения, увидели себя в состоянии располагать сокровищами Европы. Они сделали из них благородное употребление, возбудив разум художников и открыв в столице своей училище изящного. $<\ldots>$ Первосвященство Льва окружило торжественные обряды благочестия всем сиянием прекрасных искусств и возобновлением Греческого вкуса [17. С. 174-175].

Эти образы покровителей искусств, стоявших у истоков Возрождения, - правителя Флоренции Козимо Медичи, папы Льва X (Джованни Медичи) - неоднократно появятся в стихах Муравьева («Живописец», «Опыт о стихотворстве» и др.), практически всегда соседствуя с упоминанием русских меценатов - как венценосных (Петр, Екатерина), так и вельможных (Шувалов, Воронцов, Голицын и др.). Итогом их трудов стал истинный расцвет искусств, в скорейшее время приблизившихся, по убеждению писателя, к итальянским и европейским вершинам в лице А.П. Лосенкова и Д.Г. Левицкого в живописи, В.И. Баженова и И.Е. Старова в архитектуре, М.В. Ломоносова и М.М. Хераскова в поэзии, Д.С. Бортнянского и М.С. Березовского в музыке.

\section{Лumepamypa}

1. Бердяев Н.А. Философия творчества, культуры и искусства. М. : Искусство, 1994. T. $1.542 \mathrm{c}$.

2. Рутенбург В.И. Культурные и общественные связи России и Италии (XVIII и XIX века) // Россия и Италия: из истории русско-итальянских культурных и общественных связей. М. : Наука, 1968. С. 5-24.

3. Филиппо М.Д. К истории отношений между Неаполитанским королевством и Российской империей // Имагология и компаративистика. 2017. № 8. С. 5-23.

4. Фонвизин Д.И. Собрание сочинений : в 2 т. М. ; Л. : ГИХЛ, 1959. Т. 2.744 с.

5. Михаил Муравьев и его время. Казань, 2008-2017. Вып. 1-6.

6. Пильщиков И.А. Батюшков и литература Италии: филологические разыскания. М. : Языки славянской культуры, 2003.314 с.

7. Ливанова T. Русская музыкальная культура XVIII века в ее связях с литературой, театром и бытом. М. : Музгиз, 1952. Т. $1.536 \mathrm{c}$.

8. Львов Н.А. Итальянский дневник. 1781 г. : (путевые замечания) // Памятники культуры. Новые открытия. 1994. М. : Наука, 1996. С. 249-276.

9. Письма русских писателей XVIII века. Л. : Наука, 1980. 473 с.

10. Муравьев М.Н. Стихотворения. Л. : Советский писатель, 1967. 390 с.

11. Росси Л. Сентиментальная проза М.Н. Муравьева : (новые материалы) // XVIII век. СПб. : Наука, 1995. Сб. 19. С. 114-146. 
12. Головенкова Р.В. Пенсионеры-живописцы Академии художеств в XVIII веке // Вопросы художественного образования. Л. : [б.и.], 1974. Вып. VII. С. 73-83.

13. Михайлова М.Б. Русские архитекторы-пенсионеры в Италии (вторая половина XVIII - первая треть XIX века) // Россия и Италия. М. : Наука, 2000. Вып. 4: Встреча культур. С. 84-96.

14. Lappo-Danilevskij K.Yu. Об «Итальянском дневнике» Н.А. Львова // L'vov N.A. Italienisches Tagebuch: Ital'janskij dnevnik. Köln, Weimar; Wien : Böhlau, 1998. S. 3-42.

15. Муравьев М.Н. Полное собрание сочинений. СПб. : В типогр. Российской Академии, 1819. Т. 1. 381 с.

16. Лебедева О.Б., Янушкевич А.С. В.А. Жуковский и А.В. Никитенко о Сикстинской Мадонне Рафаэля: типология экфрасиса как репрезентант эстетического сознания // Вестник Томского государственного университета. Филология. 2017. № 46. C. $124-151$.

17. Муравьев М.Н. Полное собрание сочинений. СПб. : В типогр. Российской Академии, 1820. Т. 3. 325 с.

18. Горохова P.M. Торквато Тассо в России XVIII века : (материалы к истории восприятия) // Россия и Запад: из истории международных связей русской литературы. Л. : Наука, 1973. С. 148-157.

19. Горохова P.М. Ариосто в России : (материалы к истории его изучения и восприятия) // Русская литература. 1974. № 4. С. 115-126.

20. РГБ. Ф. 499. № 29.

21. Гардзонио C. Метастазио в русской поэзии XVIII - начала XIX в. // Поэтика. История литературы. Лингвистика : сб. к 70-летию Вяч. Всев. Иванова. М. : ОГИ, 1999. C. $102-114$.

22. Топоров В.Н. Из истории русской культуры. М. : Языки русской культуры, 2003. T. II: Русская литература второй половины XVIII века: исследования, материалы, публикации. М.Н. Муравьев: введение в творческое наследие. Кн. II. 928 с.

23. Муравьев М.Н. Полное собрание сочинений. СПб. : В типогр. Российской Академии, 1820. Т. 2. 404.

24. Лаппо-Данилевский К.Ю. Отрывки об искусствах М.Н. Муравьева // XVIII век. СПб. : Наука, 2002. Сб. 22. С. 347-357.

\section{ITALY IN THE HISTORIOSOPHICAL NOTIONS AND WORKS OF M.N. MURAVYOV}

Imagologiya i komparativistika - Imagology and Comparative Studies, 2018, 10, pp. 93-108. DOI: 10.17223/24099554/10/5

Vitaly S. Kiselev, Tomsk State University (Tomsk, Russian Federation). E-mail: kv-uliss@mail.ru

Keywords: Russian-Italian literary connections, 18th century, N.A. L'vov, M.N. Muravyov, Italy, Italian Renaissance, Italian opera, Italian painting, Italian literature.

The paper identifies the main motifs characteristic of the reception of Italian culture in the historical-philosophical and artistic works of M.N. Muravyov. The material for the analysis was a series of Muravyov's translations from Italian poetry, his statements about Italian poets, musicians, painters, and experiences of 
a synthetic understanding of Italian art and history. They all constitute an important layer of the writer's creative heritage, valuable both in itself and in the light of the larger and deeper interest in the Italian of Muravyov's student and apprentice K.N. Batyushkov.

N.A. L'vov, an Italomaniac who traveled to Italy, acquainted Muravyov, who had never been to Italy, with Italian culture, in particular, with opera. In his letters and essays ("Regret for Youth", "The Feonin Cycle", etc.), Muravyov regularly mentioned Italian singers and authors of operas that he could hear in the capitals.

L'vov also acquainted the young writer with Italian painting. The echoes of the Italian artistic impressions are heard in "Bernovo Letters", in the poem "You Look at Me Seduced by the Beauty of Art ...", in the article "Arts in Italy", etc.

Muravyov took interest in Italian literature in 1776, the result of which was a series of small translations from T. Tassot, G. Della Casa, G. Trissino and Metastasio. Later, in the 1780s, he made translations from Petrarca, G. Marino and L. Ariosto. The paper identifies receptive dominants in translation activities and in the comprehension of Italian poetry, especially the epic poem (Tasso, Ariosto) and "light verses". A conclusion is made about Muravyov's method that aimed to master not only a specific text, but also a certain style, a form of poetry, an art form.

This method corresponded to Muravyov's cultural and aesthetic concept; within its framework, the art of the Italian Renaissance, the main subject of his interest, served as a direct model for art in Russia, in which its own Renaissance was beginning. The writer thought about the reasons, conditions and the course of the Italian Renaissance, seeing in it an obvious model for Russia ("Bernovo Letters", articles "Successes of the Human Mind", "Arts in Italy", "Russian Art").

\section{References}

1. Berdyaev, N.A. (1994) Filosofiya tvorchestva, kul'tury i iskusstva [Philosophy of creativity, culture and art]. Vol. 1. Moscow: Iskusstvo.

2. Rutenburg, V.I. (1968) Kul'turnye i obshchestvennye svyazi Rossii i Italii (XVIII i XIX veka) [Cultural and public connections of Russia and Italy (18th and 19th centuries)]. In: Skazkin, N.D. (ed.) Rossiya i Italiya: Iz istorii russko-ital'yanskikh kul'turnykh $i$ obshchestvennykh svyazey [ Russia and Italy: From the history of Russian-Italian cultural and public connections]. Moscow: Nauka. pp. 5-24.

3. Filippo, M.D. (2017) On the history of relations between the Kingdom of Naples and the Russian Empire. Imagologiya $i$ komparativistika - Imagology and Comparative Studies. 8. pp. 5-23. (In Russian). DOI: 10.17223/24099554/8/1

4. Fonvizin, D.I. (1959) Sobranie sochineniy: $V 2$ t. [Collected Works: In 2 vols]. Vol. 2. Moscow; Leningrad: GIKHL.

5. Pashkurov, A.N. et al. (eds) (2008-2017) Mikhail Murav'yev i ego vremya [Mikhail Muravyov and his time]. Is. 1-6. Kazan: Tatar State University of Humanities and Education.

6. Pil'shchikov, I.A. (2003) Batyushkov i literatura Italii: filologicheskie razyskaniya [Batyushkov and the literature of Italy: philological investigations]. Moscow: Yazyki slavyanskoy kul'tury. 
7. Livanova, T. (1952) Russkaya muzykal'naya kul'tura XVIII veka v ee svyazyakh literaturoy, teatrom $i$ bytom [Russian musical culture of the 18th century in its relations with literature, theater and life]. Vol. 1. Moscow: Muzgiz.

8. L'vov, N.A. (1996) Ital'yanskiy dnevnik. 1781 g.: (Putevye zamechaniya) [Italian diary. 1781: (Travel notes)]. In: Pamyatniki kul'tury. Novye otkrytiya. Pis'mennost'. Iskusstvo. Arheologiya. 1994 [Monuments of Culture. New Discoveries. Writing. Art. Archaeology]. Moscow: Nauka. pp. 249-276.

9. Makogonenko, G.P. (ed.) (1980) Pis'ma russkikh pisateley XVIII veka [Letters of the 19th-century Russian writers]. Leningrad: Nauka.

10. Muravyov, M.N. (1967) Stikhotvoreniya [Poems]. Leningrad: Sovetskiy pisatel'.

11. Rossi, L. (1995) Sentimental'naya proza M.N. Murav'yeva: (Novye materialy) [Sentimental prose of M.N. Muravyov: (New materials)]. In: XVIII vek [The 18th century]. Is. 19. St. Petersburg: Nauka. pp. 114-146.

12. Golovenkova, R.V. (1974) Pensionery-zhivopistsy Akademii khudozhestv v XVIII veke [Pensioner painters of the Academy of Arts in the 18th century]. Voprosy khudozhestvennogo obrazovaniya. VII. pp. 73-83.

13. Mikhaylova, M.B. (2000) Russkie arkhitektory-pensionery v Italii (vtoraya polovina XVIII - pervaya tret' XIX veka) [Russian pensioner architects in Italy (second half of the 18th - first third of the 19th centuries)]. In: Rossiya i Italiya [Russia and Italy]. Is. 4. Moscow: Nauka. pp. 84-96.

14. Lappo-Danilevskiy, K.Yu. (1998) Ob "Ital'yanskom dnevnike" N.A. L'vova [About "The Italian Diary" of N.A. L'vov]. In: L'vov, N.A. Italienisches Tagebuch: Ital'janskij dnevnik [The Italian Diary]. Köln, Weimar; Wien: Böhlau. pp. 3-42.

15. Muravyov, M.N. (1819) Polnoe sobranie sochineniy [Complete Works]. Vol. 1. St. Petersburg: V tipogr. Rossiyskoy Akademii.

16. Lebedeva, O.B. \& Yanushkevich, A.S. (2017) V. A. Zhukovsky and A. V. Nikitenko on Raphael's Sistine Madonna: the typology of ekphrasis as a representative of aesthetic consciousness. Vestnik Tomskogo gosudarstvennogo universiteta. Filologiya - Tomsk State University Journal of Philology. 46. pp. 124-151. (In Russian). DOI: 10.17223/19986645/46/10

17. Muravyov, M.N. (1820) Polnoe sobranie sochineniy [Complete Works]. Vol. 3. St. Petersburg: V tipogr. Rossiyskoy Akademii.

18. Gorokhova, R.M. (1973) Torkvato Tasso v Rossii XVIII veka: (Materialy k istorii vospriyatiya) [Torquato Tasso in the 18th-century Russia: (Materials on the history of perception)]. In: Alekseev, M.P. (ed.) Rossiya i Zapad: Iz istorii mezhdunarodnykh svyazey russkoy literatury [Russia and the West: From the History of International Connections of Russian Literature]. Leningrad: Nauka. pp. 148-157.

19. Gorokhova, R.M. (1974) Ariosto v Rossii: (Materialy k istorii ego izucheniya i vospriyatiya) [Ariosto in Russia: (Materials on the history of study and perception)]. Russkaya literatura. 4. pp. 115-126.

20. Russian State Library. Fund 499. No. 29. (In Russian).

21. Gardzonio, S. (1999) Metastazio v russkoy poezii XVIII - nachala XIX v. [Metastasio in the Russian poetry of the 18th - early 19th centuries]. In: Poetika. Istoriya literatury. Lingvistika: Sbornik k 70-letiyu Vyach. Vsev. Ivanova [Poetics. Literary history. Linguistics: Collection for the 70th anniversary of Vyacheslav. Ivanov]. Moscow: OGI. pp. 102-114. 
22. Toporov, V.N. (2003) Iz istorii russkoy kul'tury [From the history of Russian culture]. Vol II. Book II. Moscow: Yazyki russkoy kul'tury.

23. Muravyov, M.N. (1820) Polnoe sobranie sochineniy [Complete Works]. Vol. 2. St. Petersburg: V tipogr. Rossiyskoy Akademii.

24. Lappo-Danilevskiy, K.Yu. (2002) Otryvki ob iskusstvakh M.N. Murav'yeva [Excerpts about the arts of M.N. Muravyov]. In: XVIII vek [The 18th century]. Is. 19. St. Petersburg: Nauka. pp. 347-357. 